\title{
CESPUC
}

\section{PRODUÇÕES DE SENTIDO EM TORNO DO TERMO "DEUS" NO QUARTO EVANGELHO À LUZ DA TEORIA DAS METÁFORAS CONCEPTUAIS}

\author{
Luciana Cangussu Prates *
}

O objetivo deste artigo é o de, observando as especificidades da linguagem metafórica do Apóstolo João, apresentarmos um teste metodológico da Teoria das Metáforas Conceptuais a fim de elaborarmos uma chave de leitura para o termo "Deus" no Quarto Evangelho, a qual leve em conta a noção cognitiva dos processamentos metafóricos.

Palavras-chave: Consciência. Deus. Metáfora Conceptual. Quarto Evangelho.

\section{MEANING PRODUCTION AROUND THE TERM "GOD" IN THE FOURTH GOSPEL IN LIGHT OF THE THEORY OF CONCEPTUAL METAPHORS}

The aim of this paper is, by observing some aspects of the metaphorical language of the Apostle John, to present a methodological test of the Conceptual Metaphor Theory in order to elaborate a reading key to the term "God" in the Fourth Gospel, which takes into account the cognitive notion of metaphorical processing..

Keywords : Consciousness. God. Conceptual Metaphor. Fourth Gospel.

* Doutoranda em Ciências da Religião pela Pontifícia Universidade Católica de Minas Gerais (PUC-MG). Mestre em Teologia pela Faculdade Jesuíta de Filosofia e Teologia (FAJE). Especialista em Psicologia Transpessoal pelo Instituto Renascer da Consciência (IRC). Graduada em Letras pela Universidade Federal de Minas Gerais (UFMG)..

Recebido em: 22/11/2019 | Aceito em: 09/12/2019 


\section{Luciama Cangussu Prates}

20 SEMESTRE DE $2019-$ N. 35

\section{INTRODUÇÃO}

A Teologia do Quarto Evangelho é marcada por categorias hebraicas registradas em língua grega e, dessa forma, o processo de produção de sentidos para o termo "Deus", ao longo do texto, depende do reconhecimento das influências semíticas e helenistas que inspiraram a linguagem metafórica de João. Do ponto de vista linguístico, afirma-se que, enquanto o paradigma judaico assume a metáfora como fruto da experiência, a perspectiva helênica tende a vê-la como figura de linguagem. Entretanto, a visão do judaísmo não ganhou espaço nos estudos vinculados ao fenômeno da metáfora devido à forte influência que o pensamento aristotélico exerceu sobre o assunto.

Durante séculos, a metáfora foi vista como elemento estético, cuja única função é a de ornamentar. Essa noção prevaleceu até o final do século XX, estimulando pesquisas de diferentes áreas, inclusive teológicas, a reconhecê-la e a classificá-la sem interpretá-la, já que nela não se presumia informação. Somente na década de 70 , a tradição retórica da metáfora foi questionada, sobretudo no que diz respeito aos seguintes pressupostos: ausência de valor cognitivo e falta de um significado próprio. Os críticos perceberam que, ao transcender o papel de adorno para se colocar como uma manifestação da mais fundamental operação cognitiva, a metáfora não deixa de ser linguística, mas também se vincula ao pensamento, à percepção e à ação. Foi nesse contexto que Lakoff e Johnson, na década de 80, desenvolveram a Teoria das Metáforas Conceptuais (TMC), inserida no âmbito mais abrangente das Ciências Cognitivas.

Face ao exposto, intui-se que estudar as produções de sentido em torno do termo "Deus" no Quarto Evangelho à luz da TMC tem relevância acadêmica quando se observa que esse quadro teórico, ao se encontrar no cerne de ruptura com a corrente ocidental da metáfora, resgata aspectos do ponto de vista semítico sobre esse tema tão presente no discurso de João. Assim, desenha-se o percurso deste trabalho: destacar a perspectiva hebraica da metáfora como ponto fundamental para o entendimento da Teologia do Quarto Evangelho; apresentar a TMC como lente analítica dos enunciados joaninos ligados ao termo "Deus"; elaborar uma chave de leitura sobre o Deus de João fundamentada na noção de metáfora conceptual.

\section{A METÁFORA NO QUARTO EVANGELHO}

O Quarto Evangelho tem suas raízes no Judaísmo. Essa premissa ganha valor se considerarmos que muitos aspectos linguísticos (formal/conteudista), temporais (cronológico/ psicológico), espaciais (geográfico/topográfico), bem como acentos litúrgicos, escatológicos e soteriológicos vinculados à tradição judaica apresentam-se como marcas textuais a fundamentarem o tom cristológico da teologia joanina.

Nessa perspectiva, inferimos que o Antigo Testamento e o judaísmo intertestamentário aportam os grandes temas desenvolvidos ao longo do texto joanino (BEUTLER, 2013, p. 47), os quais se convergem para a experiência de buscar Deus. Apesar de escrever em grego, sua fraseologia possui vestígios do hebraico e muitas expressões remetem aos métodos presentes nos escritos rabínicos, revelando, por isso, familiaridade com o talmud e com o midrash (DODD, 


\title{
Chane

1970, p. 74). Um estudo minucioso, especialmente de suas matérias narrativas, aponta para a hipótese de que, influenciado pela hermenêutica midráshica, João registrou os acontecimentos que envolvem o Deus de Jesus Cristo.

\begin{abstract}
A mensagem de Cristo foi transmitida em categorias de confissão de fé judaica, para convencer os judeus de que Jesus é o Messias de Israel. A novidade do Shemá é expressa em João 10,30: "Eu e o Pai somos um". João enfatiza o novo Templo, a adoração em espírito e verdade e mostra que toda a liturgia judaica encontra o seu cumprimento em Jesus. (MANNS, 1996p. 30, tradução nossa).
\end{abstract}

Tal ideia pode ser comprovada quando, por meio da análise de sua linha discursiva, percebemos que os ajustes feitos na estrutura literária foram orientados pelo modo de pensar judaico. Pela escolha da disposição textual dos eventos vinculados a Jesus Cristo, João faz midrash: ao narrar os fatos que circundam o Mistério Pascal, tem uma experiência de encontro com Deus.

Ele quis apresentar Jesus, transmitir os sinais que Ele fez e os ensinamentos que Ele deu, como eles se manifestaram e como o Espírito lhes lembrou. Se João julgou importante manter o uso de tradições judaicas apesar da novidade da mensagem evangélica que anunciava, estava consciente de que a Igreja nasceu da Sinagoga e que Jesus se dirigiu primeiro a Israel. (MANNS, 1991, p. 9, tradução nossa).

Além disso, sabemos que a linguagem simbólica do texto joanino é extremamente metafórica, mas, a partir do exposto, evidenciamos que a metáfora extrapola em muitos pontos a ideia de simples figura de linguagem, cuja função primeira é a de ornamentar um texto que se distancia do literal. Metáfora no Quarto Evangelho é especialmente fenômeno cognitivo, é modo de pensar. João não enxerga apenas o texto pelo midrash; ele enxerga o mundo dessa forma. Sua óptica parte do midrash judaico. Assim, tudo soa metafórico em João porque tudo soa como experiência de encontro com Deus.

João mantém o simbolismo bíblico de muitas maneiras. Deve-se lembrar de que o símbolo não é uma simples imagem? Ele é um elo entre as coisas visíveis e o céu invisível do criador. Todo símbolo reúne em uma expressão sintética, ou seja, plástica, o que há de mais íntimo no inconsciente e no pessoal, no social e no cósmico, no religioso e no divino. (MANNS, 1991, p. 11, tradução nossa).

Se encararmos a metáfora, nessa obra, somente como técnica retórica ou poética, perdemos a oportunidade de construir novas chaves de leitura nela contidas implicitamente. $\mathrm{O}$ Quarto Evangelho é vivo, dinâmico, cheio de ecos. Para João, metáfora é experiência que evoca a palavra inesgotável de Deus, por isso, o tom conotativo é sua grande marca linguística. Em midrash, a narração dos fatos que marcam a vida, a morte e a ressurreição de Jesus Cristo foi elaborada indicando possibilidades de encontro com Deus e, dessa forma, os sentidos emergem aos olhos dos leitores, despertando-lhes as faculdades de perceber Aquele que só é acessível porque se manifesta na vida. 


\section{CESPUC}

\section{Luciama Cangussu Prates}

Destacamos, assim, a noção basilar em torno da metáfora cultivada na matriz judaicosemítica, a qual fundamentará as próximas reflexões sobre a teologia do Quarto Evangelho. Ressaltamos que a proposta não admite qualquer pretensão de apresentar $\underline{\mathrm{o}}$ sentido a respeito do termo "Deus" no referido texto; temos apenas o desejo de sugerir uma chave de leitura para o tema, tendo como base uma abordagem em torno da metáfora.

\section{A TEORIA DAS METÁFORAS CONCEPTUAIS}

Também conhecida como Teoria Cognitiva da Metáfora, a TCM foi proposta por Lakoff \& Johnson em 1980 e está inserida no âmbito mais abrangente das Ciências Cognitivas. Esse novo material acadêmico está, portanto, no cerne da ruptura que se deu em relação a uma tradição milenar sobre a metáfora, dando destaque à sua natureza conceptual. Em outras palavras, passou-se a considerar que a metáfora pertence primeiramente ao domínio do pensamento e só depois ao domínio da linguagem, revelando-se um mecanismo importante na compreensão e na explicação da cognição humana. Além disso, como mencionado anteriormente, porque tratam de uma questão de pensamento, os autores defendem a ideia de que a metáfora conceptual integra não só a linguagem poética, mas também a linguagem cotidiana e de várias áreas do conhecimento.

As metáforas conceptuais são em larga medida responsáveis pela nossa "topologia cognitiva", influenciam a nossa maneira de agir e realizam-se quer em obras de natureza artística quer em instituições, mitos e práticas sociais. Essas realizações refletem a estrutura do nosso sistema conceptual e simultaneamente reforçam-na, oferecendo novas bases, na experiência, para a validade dessas metáforas (além da experiência biológica, também as criações humanas podem proporcionar uma base experiencial). (AMARAL, 2001, p. 246.)

Lakoff e Johnson explicam que a metáfora, na sua essência, é um mecanismo conceptual e cognitivo que permite explicar uma ideia em termos de outra, partindo da nossa experiência corporal para categorizar entidades e eventos mais abstratos. Assim, esse mecanismo caracterizase pela relação entre dois domínios conceptuais diferentes, na qual elementos de um domínio mais concreto, Domínio de Origem (Source Domain), são transferidos para outro mais abstrato, Domínio Alvo (Target Domain). Nessa linha de raciocİnio que assumem, as novas experiências só podem ser entendidas na medida em que se integram a conhecimentos anteriores.

As metáforas presentes na língua são uma manifestação da maneira como entendemos e conceptualizamos determinados conceitos. Trata-se de uma operação cognitiva, na qual empregamos um domínio experiencial mais concreto, estreitamente ligado à experiência com nosso próprio corpo e o mundo em que vivemos, para compreender/conceptualizar um domínio mais abstrato, cuja natureza da experiência humana não permite uma representação direta. São, portanto, nossas experiências corpóreas, de diferentes dimensões, que, sendo recorrentes e co-ocorrentes, geram metáforas que subjazem à nossa forma de falar. (LIMA, 2001, p. 108) 
A fim de facilitar o entendimento de como emergem as metáforas conceptuais, propõese o conceito de "mapeamento" (Mapping) entre dois domínios conceptuais. Nesse conceito, um domínio mental é conceptualizado em termos de outro domínio. Isto significa que um Domínio de Origem, de natureza concreta e experiencial vivido por determinado sujeito, serve-lhe como uma maneira de explicar entidades que pertencem a um Domínio Alvo, o qual possui um caráter mais abstrato. $\mathrm{O}$ ato de cartografar se dá, desse modo, por meio de correspondências ontológicas entre domínios conceptuais, que encontram fundamento nas interações perceptuais humanas, nas experiências corporais e nas manipulações de objetos.

Temos, assim, o estabelecimento de uma projeção unidirecional, a qual é baseada na memória de longo prazo: DOMÍNIO DE ORIGEM $\rightarrow$ DOMÍNIO ALVO. Esse percurso de transposição de ideias, por conseguinte, gera a metáfora cognitiva DOMíNIO ALVO $\rightarrow$ DOMÍNIO DE ORIGEM. Nesse ponto, convém fazer uma distinção entre as noções de "expressão metafórica" e "metáfora conceptual". Uma expressão metafórica consiste numa expressão linguística que veicula uma metáfora conceptual, isto é, trata-se de uma manifestação de um pensamento metafórico por meio da linguagem. Por outro lado, a metáfora conceptual não é uma expressão linguística, mas antes um mecanismo mental que se constitui em imagens e que permite ao indivíduo estabelecer projeções entre domínios distintos, que, no nível linguístico, podem se realizar de várias maneiras.

De acordo com a Teoria das Metáforas Conceptuais (...) a metáfora é um fenômeno cognitivo, que consiste na conceptualização de um domínio mental através de outro. Os autores estabelecem, assim, uma distinção entre metáfora ou metáfora conceptual, i.e., conjunto de correspondências/ sistemáticas entre dois domínios conceptuais (um domínio-fonte/-origem e um domínio-alvo/-objetivo) e expressies metafóricas, definidas como expressies linguísticas através das quais se manifesta a conceptualização metafórica subjacente e que são sancionadas por ela. (AMARAL, 2001, p. 245.)

Nesse contexto, Lakoff e Johnson enquadram pedagogicamente as inúmeras metáforas conceptuais. Os autores criaram as seguintes definições (LAKOFF \& JOHNSON, 1980):

a) METÁFORAS CONCEPTUAIS ESTRUTURAIS são aquelas que se organizam quando apenas um conceito é estruturado metaforicamente em termos de outro, como já explicado anteriormente. Como exemplicação, tem-se: IDEIA É UM OBJETO.

b) METÁFORAS CONCEPTUAIS ORIENTACIONAIS são aquelas que organizam todo um sistema de conceitos em relação a outro, geralmente vinculando-se à orientações espaciais, como: para cima/para baixo; dentro/fora; frente/trás; em cima de/embaixo de; on/off; fundo/ raso; central/periférico. Como exemplo, tem-se: FELIZ É PARA CIMA.

c) METÁFORAS CONCEPTUAIS ONTOLÓGICAS são aquelas que se organizam a partir das experiências físicas com objetos, especialmente com o corpo. Ao transcenderem uma compreensão dos conceitos baseados na orientação espacial, favorecem maneiras de se conceber eventos, atividades, emoções e ideias como entidades e substâncias. Com elas, criam- 
se referências, como quantificar objetos e sensações, identificar aspectos e causas, bem como traçar metas e objetivos. Por isso, são mais elaboradas: A MENTE É UMA MÁQUINA.

Em síntese, a TMC mostra que a metáfora está infiltrada na vida cotidiana, não somente na linguagem, mas também no pensamento e na ação. Enfatiza que ela transcende à ideia de ornamentação, pois carrega em si um valor informativo. Defende que o sistema conceptual ordinário é fundamentalmente metafórico e que tal característica estrutura as faculdades de percepção dos seres humanos, norteando comportamentos perante o mundo que os rodeia. Nesse sentido, defende que é uma questão de metáfora o fato de, sempre influenciados por determinada cultura, os processamentos linguístico-cognitivos serem os responsáveis pela definição de uma realidade específica.

A TMC fundamenta, além disso, que a essência da metáfora é compreender e experienciar uma coisa em termos de outra. Admite que grande parcela do sistema conceptual sobre determinado tema organiza uma série de expressões metafóricas presentes nas diversas línguas, as quais, por sua vez, também estão ligadas de maneira sistemática a conceitos metafóricos, compreensões metafóricas e atividades metafóricas (LAKOFF \& JOHNSON, 2002, p. 4550). Por fim, afirma que uma metáfora conceptual só pode ser legitimada enquanto tal se for confirmada por diversas ocorrências no nível linguístico, ou seja, salienta a necessidade de haver uma relação produtiva entre Domínio de Origem e Domínio Alvo.

Ao optarmos pela TMC como ferramenta teórico-metodológica para análise do processo de estruturação discursivo-metafórica do Quarto Evangelho, pretendemos cartografar os possíveis Domínios de Origem que influenciaram as expressões metafóricas joaninas vinculadas ao tema Deus, apresentado, a partir de agora, como o Domínio Alvo DEUS. Por essa proposta, assumimos que cada possível Domínio de Origem encontrado representará uma dimensão de vivência mais concreta e material, a qual pode ter fundamentado, do ponto de vista discursivo, a linguagem e o pensamento de João que favorecem a produção de sentidos em torno de sua Teologia. Ressaltamos, ainda, que essa base experiencial será nosso ponto de partida para compreendermos como o texto joanino revela o termo "Deus" que, do ponto de vista linguístico, é mais abstrato e imaterial.

\section{DEUS NA LINGUAGEM METAFÓRICA DO QUARTO EVANGELHO}

$\mathrm{Na}$ ambiência comunicativa, reconhecemos João como aquele que, ao se instanciar como evangelista, narra, para uma comunidade heterogênea de leitores, situações sobre o Deus de Jesus. Por meio da leitura, esses interlocutores podem coproduzir sentidos para Deus que sejam compatíveis com as suas experiências culturais.

Retomando a TMC, enumeramos os traços mais relevantes no processo de identificação de uma metáfora conceptual: é um mecanismo conceptual e cognitivo; permite explicar uma ideia em termos de outra; parte da experiência corporal para categorizar entidades e eventos abstratos; relaciona domínios conceptuais diferentes; projeta de modo unidirecional elementos do domínio concreto ao domínio mais abstrato; organiza uma série de expressões 


\section{Luciama Cangussu Prates}

2O SEMESTRE DE $2019-$ N. 35

metafóricas presentes em diversas línguas; subjaz à forma de falar/ouvir e de escrever/ler; pertence à dimensão da linguagem, mas também ao pensamento e à ação; transcende a ideia de ornamentação; carrega um valor informativo; estrutura a faculdade de percepção dos seres humanos; sofre influência da cultura; só é compreendida na medida em que se integra a conhecimentos anteriores; está infiltrada na vida cotidiana; define uma realidade específica.

E, no intuito de enfatizarmos como o Quarto Evangelho é acolhido neste momento, ressaltamos alguns pontos significativos: é um texto eminentemente marcado pela tradição bíblica, a qual encara a metáfora como modo de pensar; foi elaborado em uma situação de conflito entre judeus e cristãos; está escrito em grego, mas apresenta nitidamente, por tal influência judaica, categorias do mundo hebraico; é uma releitura de um fato histórico no qual a figura de Jesus Cristo é protagonista de uma Teologia cuja perspectiva central é soteriológica; destina-se a uma comunidade de leitura heterogênea composta de judeus, gregos e romanos; situa-se, do ponto de vista literário, entre a narração e o drama; é marcado por uma linguagem metafórica repleta de figuras e de imagens, as quais estão organizadas por meio de sinais e de símbolos.

Isto posto, refletimos sobre o aspecto cristológico da Teologia de João, a qual demonstra pontos de convergência entre o aparente Domínio de Origem JESUS, que é culturalmente mais concreto e sensorial, e o Domínio Alvo DEUS, que não é plenamente apreensível no nível linguístico-cognitivo. Pela leitura do Quarto Evangelho, temos a impressão de que existe uma projeção de natureza conceptual JESUS $\square$ DEUS, mas isto não é o bastante para apontar DEUS É JESUS como uma metáfora conceptual, já que esta, para ser legitimada, teria de se revelar em expressies metafóricas que a confirmassem no nível do discurso. Procurando, então, uma prova linguística que justifique a ideia de que JESUS seja um Domínio de Origem para o Domínio Alvo DEUS, recorremos às bases categoriais da Tradição do Antigo Testamento, cuja influência marca o modo de pensar midráshico do texto joanino. Enfatizamos que, no Antigo Testamento, encontra-se uma constelação de Domínios de Origem, muito articulada a partir da experiência concreta do peregrino hebreu que implicava sensações físicas de fome, sede, calor, cansaço e medo, as quais, por sua vez, apontavam para outro gênero de vivência, abstrata e espiritual, relacionada a Deus.

Ademais, como já mencionado, o Quarto Evangelho, apesar de ser um registro em língua grega, está marcado por essas categorias hebraicas e João, quando desenvolve sua Teologia em torno do templo e da forma como Jesus cumpre seus propósitos, dá elementos à comunidade para percebê-Lo em sua dimensão messiânica e mostra que o Cristo não se distancia da tradição do Deus de Israel. Pelo contrário: Jesus é o novo templo e a nova Torah.

Em Jesus, penso, podemos ver a imagem bíblica de YHWH tomando forma: o Deus amoroso desnudando seu santo braço (Isaías 52,10) para fazer o trabalho que ninguém mais poderia fazer; o Deus criador dando vida nova; o Deus que trabalha através de seu mundo criado; e de forma suprema através das criaturas humanas; o Deus fiel habitando no meio de seu povo; o Deus compassivo, se opondo a toda forma de maldade, mas mostrando compaixão e misericórdia por aqueles que realizam o mal, querendo transformar suas vidas. "Como pastor ele cuida do seu rebanho; com o braço ajunta os cordeiros e os carrega no colo; conduz com 


\section{Chane

cuidado as ovelhas que amamentaram suas crias" (Isaías 40,11). Esse é o retrato que o Antigo Testamento faz sobre YHWH; contudo, ele se encaixa perfeitamente na pessoa de Jesus. (WRIGHT, 2012, p. 137.)

Seguindo essa perspectiva, buscando compreender se a leitura do Quarto Evangelho favorece a emersão da metáfora conceptual DEUS É JESUS, temos o presságio de que o Domínio de Origem JESUS, no nível linguístico-cognitivo, pode funcionar no texto joanino como a síntese que reúne em si os Domínios de Origem presentes na tradição bíblica para se referir ao Domínio Alvo DEUS. A seguir, verificamos essa hipótese pelo resgate de expressões metafóricas do Antigo Testamento que se associam àquelas presentes nessa parte do Novo Testamento e, a partir disso, destacamos as possíveis metáforas conceptuais para Deus.

os a tentativa lembrando que, ao longo dos livros da Bíblia Hebraica, a mentalidade dos semitas experimentava Deus, linguisticamente, em termos de feições humanas (face, nariz, ouvidos, boca, lábios, língua, olhos, braços, mãos, pés, costas). Para eles, o Deus de Israel é um Ser vivo e pessoal que se manifesta por meio de revelações sensíveis (BITTENCOURT, 1956, p. 55).

Os israelitas, pouco afeitos à abstração, dificilmente se desvencilhavam de concepções de ordem sensível, até mesmo ao falarem de Deus. Reconheciam, sim, que o Criador não é como o homem, mas dificilmente percebiam o que o fato de "Deus ser Deus, e não homem" (cf. Os 11,9) implicava para a inteligência. Por isto, referindo-se ao Todo-Poderoso usavam copiosamente os vocábulos sensíveis que designam as coisas corpóreas. (BITTENCOURT, 1956, p. 54)

No quadro abaixo, apresentam-se expressões metafóricas do Antigo Testamento para mostrar como Deus é experimentado a partir da experiência humana de ter um corpo físico e, em paralelo, articulam-se as projeções de domínios nelas presentes com a ideia da Encarnação de Jesus.

Mais uma ligeira observação: quem reflita sobre os antropomorfismos bíblicos à luz do grande plano salvífico de Deus, em última análise neles reconhecer como que prenúncios da Encarnação. A tendência a atribuir ao altíssimo aspecto e afetos humanos é, sem dúvida, muito natural à nossa mente, em particular à do indivìduo primitivo; contudo, no povo de Israel, ela foi por Deus utilizada para inculcar uma verdade que os filósofos da antiguidade jamais conceberam adequadamente, verdade que havia de ressoar por excelência na plenitude dos tempos, quando o Filho de Deus tomou carne humana. (BITTENCOURT, 1956, p. 57) 


\section{CESPUC \\ 20 SEMESTRE DE $2019-$ N. 35}

\section{Luciama Cangussu Prates}

Quadro 1: DEUS É CORPO

\begin{tabular}{|c|c|c|c|c|}
\hline $\begin{array}{c}\text { EXPRESSÕES METAFÓRICAS } \\
\text { DO ANTIGO TESTAMENTO } \\
\rightarrow\end{array}$ & $\begin{array}{l}\text { PROJEÇÃO } \\
\text { MAPPING } \\
\rightarrow\end{array}$ & $\begin{array}{l}\text { METÁFORA } \\
\text { CONCEPTUAL } \\
\quad \rightarrow \leftarrow\end{array}$ & $\begin{array}{c}\text { PROJEÇÃO } \\
\text { MAPPING } \\
\leftarrow\end{array}$ & $\begin{array}{c}\text { EXPRESSÕES } \\
\text { METAFÓRICAS } \\
\text { DO QUARTO } \\
\text { EVANGELHO } \\
\leftarrow \\
\end{array}$ \\
\hline $\begin{array}{l}\text { Iahweh, então, falava com Moisés } \\
\text { face a face, como um homem fala } \\
\text { com seu amigo. (Ex } 33,11)\end{array}$ & $\begin{array}{c}\mathrm{BOCA} \rightarrow \\
\text { DEUS } \\
\mathrm{FACE} \rightarrow \text { DEUS }\end{array}$ & \multirow{7}{*}{$\begin{array}{l}\text { DEUS } \\
\text { É } \\
\text { CORPO }\end{array}$} & \multirow{7}{*}{$\begin{array}{l}\text { CARNE } \rightarrow \\
\text { DEUS }\end{array}$} & \multirow{7}{*}{$\begin{array}{c}\text { E o verbo se fez } \\
\text { carne e tabernaculou } \\
\text { entre nós, e } \\
\text { contemplamos a sua } \\
\text { glória, semelhante a } \\
\text { de unigênito junto } \\
\text { do Pai, pleno de } \\
\text { graça e verdade. } \\
\text { (Jo } 1,14)\end{array}$} \\
\hline $\begin{array}{c}\text { De suas narinas subiu uma fumaça e } \\
\text { da sua boca um fogo que devorava. (S1 } \\
17,9)\end{array}$ & $\begin{array}{c}\text { NARINAS } \rightarrow \\
\text { DEUS }\end{array}$ & & & \\
\hline $\begin{array}{l}\text { Samuel ouviu tudo o que o povo disse } \\
\text { e contou ao ouvido de Iahweh (I Sam } \\
8,21 \text { ) }\end{array}$ & $\begin{array}{l}\text { OUVIDOS } \rightarrow \\
\quad \text { DEUS }\end{array}$ & & & \\
\hline $\begin{array}{l}\text { É uma terra de que Iahweh teu Deus } \\
\text { cuida. Os olhos de Iahweh teu Deus } \\
\text { estão sempre fixos nela, do início ao } \\
\text { fim do ano. (Dt } 11,12 \text { ) }\end{array}$ & $\begin{array}{l}\text { OLHOS } \rightarrow \\
\text { DEUS }\end{array}$ & & & \\
\hline $\begin{array}{l}\text { Depois tirarei a palma da mão e me } \\
\text { verás pelas costas. Minha face, porém, } \\
\text { não se pode ver. (Ex } 33,23)\end{array}$ & $\begin{array}{l}\mathrm{MÃO} \rightarrow \text { DEUS } \\
\text { COSTAS } \rightarrow \\
\text { DEUS } \\
\text { FACE } \rightarrow \\
\text { DEUS }\end{array}$ & & & \\
\hline $\begin{array}{c}\text { Se penetrarem no Xeol, lá minha mão } \\
\text { os prenderá. (Dt } 11,12)\end{array}$ & MÃO $\rightarrow$ DEUS & & & \\
\hline $\begin{array}{c}\text { Iahweh é lento na ira, mas grande } \\
\text { em poder. Mas a nada deixa Iahweh } \\
\text { impune. Na tormenta e na tempestade } \\
\text { é o seu caminho, a nuvem é a poeira } \\
\text { de seus pés. }(\mathrm{Na} 1,3)\end{array}$ & PÉS $\rightarrow$ DEUS & & & \\
\hline
\end{tabular}

A relação estabelecida entre esses domínios também revela o caráter metonímico da metáfora conceptual DEUS É CORPO.

As categorias mais concretas BOCA, FACE, NARINA, OUVIDOS, OLHOS, MÃO, COSTAS, PÉS e CARNE se vinculam ao Domínio de Origem CORPO e este, quando projetado para o Domínio Alvo DEUS, evidencia a metáfora conceptual DEUS É CORPO. Com essa dimensão corpórea projetada para Deus, afirma-se que os hebreus, sendo mais concretos do que abstrativos, também experimentavam-No em termos de papeis sociais (rei, guerreiro, pastor, agricultor, sábio, pai), os quais se tornavam referência a partir da atividade que exerciam no grupo de convivência. 


\section{CESPUC}

\section{Luciama Cangussu Prates}

Consequentemente às premissas até aqui expostas, tendia o semita a focalizar, acima de tudo, a importância vital, a mensagem prática, que pudesse estar ligada às pessoas ou coisas apreendidas. O orador ou o escritor, ao dissertarem, baseavam-se muito na sua experiência pessoal e visavam despertar impressões semelhantes, muito vivas, nos seus ouvintes e leitores. Procuravam transmitir da maneira mais penetrante possível um estado de alma. Isto faz que uma página de literatura semita seja impregnada de movimento, variedade de pessoas e coisas que se sucedem com realismo; emoções, afetos diversos a perpassavam. Já que a linguagem semita ficava particularmente ligada à experiência, diz-se que ela evocava ainda mais do que exprimia. (BITTENCOURT, 1956, p. 42-43)

Agora, apresentam-se expressões metafóricas do Antigo Testamento que ressaltam o quanto o exercício de papeis sociais funcionava como base para os hebreus experimentarem Deus. A noção de participar, como membro da comunidade, das atividades da época, liga-se, de certa forma, à maneira como João apresenta a relação especial que Jesus Cristo tem com Deus.

Quadro 2 - DEUS É AUTORIDADE

\begin{tabular}{|c|c|c|c|c|}
\hline $\begin{array}{l}\text { EXPRESSÕES METAFÓRICAS } \\
\text { DO ANTIGO TESTAMENTO } \\
\longrightarrow\end{array}$ & $\begin{array}{l}\text { PROJEÇÃO } \\
\text { MAPPING } \\
\rightarrow\end{array}$ & $\rightarrow \leftarrow$ & $\begin{array}{c}\text { PROJEÇÃO } \\
\text { MAPPING } \\
\leftarrow\end{array}$ & $\begin{array}{c}\text { EXPRESSÕES } \\
\text { METAFÓRICAS DO } \\
\text { QUARTO EVANGELHO } \\
\leftarrow\end{array}$ \\
\hline $\begin{array}{c}\text { Quem é este rei da glória? É Iahweh, } \\
\text { o forte e valente, Iahweh, o valente } \\
\text { das guerras. }(\mathrm{S} 124,10)\end{array}$ & \multirow[b]{2}{*}{$\mathrm{REI} \rightarrow \mathrm{DEUS}$} & \multirow{5}{*}{ AUTORIDADE } & \multirow[b]{2}{*}{$\mathrm{REI} \rightarrow \mathrm{DEUS}$} & $\begin{array}{l}\text { Respondeu-lhe Natanael: } \\
\text { Mestre, tu és o filho de Deus, tu } \\
\text { és o rei de Israel. } \\
\text { (Jo 1,49) }\end{array}$ \\
\hline $\begin{array}{c}\text { Tu, porém, ó Deus, és meu rei desde } \\
\text { a origem, quem opera libertação pela } \\
\text { terra. }(\mathrm{Sl} 74,12)\end{array}$ & & & & $\begin{array}{c}\text { Jesus (porém) tendo } \\
\text { encontrando um jumentinho } \\
\text { sentou nele -assim como está } \\
\text { escrito: Não temas, filha de } \\
\text { Sião, eis teu rei sentado num } \\
\text { potro de jumento. } \\
\text { (Jo 12,14-15) }\end{array}$ \\
\hline $\begin{array}{l}\text { Ele constituirá uma casa a meu nome; } \\
\text { será para mim um filho e eu serei } \\
\text { para ele um pai; firmarei para sempre } \\
\text { o trono de sua realiza sobre Israel . (I } \\
\text { Cr } 22,10)\end{array}$ & \multirow{3}{*}{$\mathrm{PAI} \rightarrow \mathrm{DEUS}$} & & & $\begin{array}{l}\text { Não mais vos chamo servos, } \\
\text { porque o servo não sabe o que } \\
\text { faz o seu senhor. A vós porém } \\
\text { chamei de amigos, porque } \\
\text { tudo o que ouvi do Pai vos fiz } \\
\text { conhecer. } \\
\text { (Jo } 15,15)\end{array}$ \\
\hline $\begin{array}{l}\text { E eu dizia: Como te situarei entre os } \\
\text { filhos? Dar-te-ei uma terra agradável, a } \\
\text { herança mais preciosa das nações. E eu } \\
\text { dizia: Vós me chamareis “Meu Pai", e } \\
\text { não vos afastareis de mim. (Jr 3,19) }\end{array}$ & & & $\mathrm{PAI} \rightarrow$ DEUS & \\
\hline $\begin{array}{l}\text { Porque Iahweh repreende os que ele } \\
\text { ama, como um pai ao filho que preza. } \\
\text { (Pr } 3,12)\end{array}$ & & & & \\
\hline
\end{tabular}




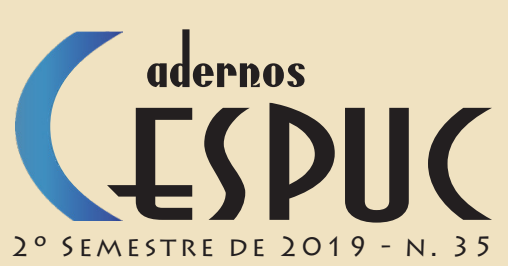

Luciama Cangussu Prates

20 SEMESTRE DE $2019-$ N. 35

\begin{tabular}{|c|c|c|c|c|}
\hline $\begin{array}{l}\text { EXPRESSÕES METAFÓRICAS } \\
\text { DO ANTIGO TESTAMENTO } \\
\longrightarrow\end{array}$ & $\begin{array}{l}\text { PROJEÇÃO } \\
\text { MAPPING } \\
\longrightarrow\end{array}$ & $\begin{array}{c}\text { METÁFORA } \\
\text { CONCEPTUAL } \\
\longrightarrow \leftarrow\end{array}$ & $\begin{array}{l}\text { PROJEÇÃO } \\
\text { MAPPING } \\
\leftarrow\end{array}$ & $\begin{array}{c}\text { EXPRESSÕES } \\
\text { METAFÓRICAS DO } \\
\text { QUARTO EVANGELHO } \\
\leftarrow\end{array}$ \\
\hline $\begin{array}{c}\text { Eu os plantarei em sua terra e não } \\
\text { serão mais arrancados de sua terra, que } \\
\text { eu lhes dei, disse Iahweh teu Deus. } \\
(\text { Am 9,15) }\end{array}$ & \multirow{3}{*}{$\begin{array}{l}\text { AGRICULTOR } \\
\rightarrow \text { DEUS }\end{array}$} & \multirow{7}{*}{$\begin{array}{c}\text { DEUS } \\
\text { É } \\
\text { AUTORIDADE }\end{array}$} & \multirow{3}{*}{$\begin{array}{l}\text { AGRICULTOR } \\
\rightarrow \text { DEUS }\end{array}$} & $\begin{array}{c}\text { Eu sou a videira verdadeira, e } \\
\text { meu Pai é o agricultor. Todo } \\
\text { ramo em mim que não produz } \\
\text { fruto, ele o tira e todo ramo que } \\
\text { produz fruto ele o purifica, para } \\
\text { que produza mais fruto. } \\
\text { (Jo 15,1-2) }\end{array}$ \\
\hline $\begin{array}{l}\text { Senhor é o meu pastor, nada me } \\
\text { faltará. (S1 23,1) }\end{array}$ & & & & $\begin{array}{l}\text { Eu sou o pastor de valor. O } \\
\text { pastor de valor põe sua alma } \\
\text { pelas suas ovelhas. (Jo } 10,11)\end{array}$ \\
\hline $\begin{array}{l}\text { Quanto a nós, teu povo, rebanho do } \\
\text { teu pasto, nós te celebramos para } \\
\text { sempre, e } \\
\text { de geração a geração proclamaremos } \\
\text { teu louvor! (S1 79,13) }\end{array}$ & & & & $\begin{array}{c}\text { E outras ovelhas tenho que } \\
\text { não são deste aprisco, também } \\
\text { aquelas devo conduzir e } \\
\text { elas escutam minha voz e se } \\
\text { tornarão um rebanho, um } \\
\text { pastor. } \\
(\text { Jo } 10,16)\end{array}$ \\
\hline $\begin{array}{l}\text { Deus dos Exércitos, volta atrás! Olha } \\
\text { do céu e vê, vistita esta vinha: protege } \\
\text { o que tua direita plantou! (S1 80,15) }\end{array}$ & $\begin{array}{l}\text { GUERREIRO } \rightarrow \\
\text { DEUS } \\
\text { AGRICULTOR } \rightarrow \\
\text { DEUS }\end{array}$ & & \multirow[t]{2}{*}{$\begin{array}{l}\text { GUERREIRO } \\
\quad \rightarrow \text { DEUS }\end{array}$} & \multirow{2}{*}{$\begin{array}{l}\text { Isso vos tenho falado para que } \\
\text { em mim tenhais paz. No mundo } \\
\text { tendes aflição. Mas tende } \\
\text { coragem, eu venci o mundo. } \\
\text { (Jo 16,33) }\end{array}$} \\
\hline $\begin{array}{l}\text { Iahweh é um guerreiro, Iahweh é o } \\
\text { seu nome! (Ex 15:3) }\end{array}$ & $\begin{array}{l}\text { GUERREIRO } \rightarrow \\
\text { DEUS }\end{array}$ & & & \\
\hline $\begin{array}{l}\text { Confia em Iahweh com todo o } \\
\text { teu coração, não te fies em tua } \\
\text { própria inteligência; em todos os } \\
\text { teus caminhos, reconhece-o, e ele } \\
\text { endireitará as tuas veredas. (Pr } 3,5)\end{array}$ & \multirow[t]{2}{*}{ SÁBIO $\rightarrow$ DEUS } & & \multirow[t]{2}{*}{$\begin{array}{l}\mathrm{PAI} \rightarrow \text { DEUS } \\
\mathrm{SÁBIO} \rightarrow \\
\text { DEUS }\end{array}$} & $\begin{array}{l}\text { Pois como o Pai tem a vida } \\
\text { em si mesmo, assim também } \\
\text { deu ao Filho ter a vida; e deu- } \\
\text { lhe autoridade para fazer o } \\
\text { julgamento porque é o Filho do } \\
\text { Homem. } \\
\text { (Jo 5, 26-27) }\end{array}$ \\
\hline $\begin{array}{l}\text { Donde vem, pois, a Sabedoria? Onde } \\
\text { está o lugar da Inteligência? (...) Só } \\
\text { Deus conhece o caminho para ela, só } \\
\text { ele sabe o seu lugar. (Jó } 28,20 \text { e } 23 \text { ) }\end{array}$ & & & & $\begin{array}{l}\text { Se as coisas terrenas disse a vós } \\
\text { e não acreditais, como, se digo- } \\
\text { vos as celestes, acreditareis? } \\
\left(\mathrm{J}_{\mathrm{O}} 3,12\right)\end{array}$ \\
\hline
\end{tabular}

As categorias mais concretas REI, PAI, AGRICULTOR, PASTOR, GUERREIRO, SÁBIO se vinculam ao Domínio de Origem AUTORIDADE e este, quando projetado para o Domínio 


\section{Luciama Cangussu Prates}

2O SEMESTRE DE $2019-$ N. 35

Alvo DEUS, evidencia a metáfora conceptual DEUS É AUTORIDADE.

Ainda, enfatiza-se que o Povo de Israel experimentava Deus em termos de instâncias religiosas (Jerusalém, Monte Sião, tabernáculo, templo e seus acessórios, rituais litúrgicos). Isto é tão forte na cognição judaica que, o próprio evangelista, pelo modo de pensar midráshico, deixa pistas de que organizou a narrativa a partir de sua experiência com o Templo de Jerusalém.

Existem teorias de que a dinâmica do enredo se inicia com o Prólogo em Jol,1-18, simbolizando o adro, porta de entrada do templo. Desenvolve-se em Jo 1,19 até Jo 12 no conhecido pátio dos gentios, local universal, considerado, na época, o templo para as nações, onde todos podiam ir e dialogar, visto como espaço da interação que Israel deveria ouvir. Nessa parte do texto, por exemplo, Jesus está em interação com a mulher samaritana. Incrementase em Jo 13-17 no Lugar Santo, local onde só os sacerdotes iniciados poderiam entrar após um seríssimo ritual de purificação. Nessa parte do texto, Jesus tem diálogos intimistas com os apóstolos e se põe em comunhão com eles. Eleva-se em Jo 18-20 no Santos dos Santos, local onde só o sumo-sacerdote entrava uma vez por ano no dia do perdão. Nessa parte do texto, Jesus é preso, indo sozinho rumo à cruz. Culmina-se em Jo 21 "acima do templo", no qual Jesus ressuscitado dialoga com os seus.

Diante disso, demonstra-se na tabela abaixo como o intercruzamento dessas observações favorecem a percepção de que João encerra a experiência judaica de Deus no Mistério Pascal.

Quadro 3 - DEUS É LUGAR

\begin{tabular}{|c|c|c|c|c|}
\hline $\begin{array}{c}\text { EXPRESSÕES METAFÓRICAS } \\
\text { DO ANTIGO TESTAMENTO } \\
\rightarrow\end{array}$ & $\begin{array}{l}\text { PROJEÇÃO } \\
\text { MAPPING } \\
\rightarrow\end{array}$ & $\begin{array}{c}\text { METÁFORA } \\
\text { CONCEPTUAL } \\
\longrightarrow \leftarrow\end{array}$ & $\begin{array}{c}\text { PROJEÇÃO } \\
\text { MAPPING } \\
\leftarrow\end{array}$ & $\begin{array}{c}\text { EXPRESSÕES } \\
\text { METAFÓRICAS } \\
\text { DO QUARTO EVANGELHO } \\
\leftarrow\end{array}$ \\
\hline $\begin{array}{l}\text { Iahweh é bom; ele é abrigo } \\
\text { no dia da tribulação. Ele } \\
\text { conhece aqueles que nele se } \\
\text { refugiam. }(\mathrm{Na}, 1,7)\end{array}$ & $\begin{array}{c}\text { ABRIGO } \rightarrow \\
\text { DEUS }\end{array}$ & \multirow[b]{2}{*}{$\begin{array}{l}\text { DEUS } \\
\text { É } \\
\text { LUGAR }\end{array}$} & \multirow[b]{2}{*}{$\begin{array}{c}\text { CASA } \rightarrow \\
\text { DEUS }\end{array}$} & $\begin{array}{c}\text { E aos vendedores das } \\
\text { pombas disse: Tirai isto } \\
\text { daqui, não façais da casa } \\
\text { de meu Pai uma casa de } \\
\text { comércio. } \\
\text { (Jo 2,16) }\end{array}$ \\
\hline $\begin{array}{l}\text { Ele disse: Iahweh é a minha } \\
\text { rocha, minha fortaleza, meu } \\
\text { libertador, meu Deus, meu } \\
\text { rochedo, nele me abrigo; } \\
\text { meu escudo, minha arma de } \\
\text { salvação, minha fortaleza, } \\
\text { meu refúgio, meu salvador, } \\
\text { tu me salvas da violência. } \\
(2 \mathrm{Sm}, 22,2)\end{array}$ & $\begin{array}{c}\text { ABRIGO } \rightarrow \\
\text { DEUS }\end{array}$ & & & $\begin{array}{c}\text { Na casa de meu Pai há } \\
\text { muitas moradas. Se não, } \\
\text { ter-vos-ia dito (que): "Vou } \\
\text { preparar-vos um lugar"? } \\
\text { (Jo 14,2) }\end{array}$ \\
\hline
\end{tabular}




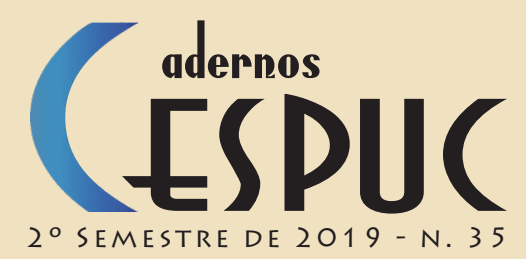

Luciama Cangussu Prates

\begin{tabular}{|c|c|c|c|c|}
\hline $\begin{array}{c}\text { EXPRESSÕES METAFÓRICAS } \\
\text { DO ANTIGO TESTAMENTO } \\
\rightarrow\end{array}$ & $\begin{array}{l}\text { PROJEÇÃO } \\
\text { MAPPING } \\
\rightarrow\end{array}$ & $\begin{array}{c}\text { METÁFORA } \\
\text { CONCEPTUAL } \\
\rightarrow \leftarrow\end{array}$ & $\begin{array}{l}\text { PROJEÇÃO } \\
\text { MAPPING } \\
\leftarrow\end{array}$ & $\begin{array}{c}\text { EXPRESSÕES } \\
\text { METAFÓRICAS } \\
\text { DO QUARTO EVANGELHO } \\
\leftarrow\end{array}$ \\
\hline $\begin{array}{c}\text { Bendito seja Iahweh, o meu } \\
\text { rochedo, que treina minhas } \\
\text { mãos para a batalha e meus } \\
\text { dedos para a guerra; meu } \\
\text { amor e minha fortaleza, } \\
\text { minha torre forte e meu } \\
\text { libertador, o escudo em } \\
\text { que me abrigo e que a } \\
\text { mim submete os povos. (S1 } \\
144,1-2 \text { ) }\end{array}$ & $\begin{array}{l}\text { FORTALEZA } \rightarrow \\
\quad \text { DEUS } \\
\text { TORRE FORTE } \\
\rightarrow \text { DEUS }\end{array}$ & \multirow{5}{*}{$\begin{array}{l}\text { DEUS } \\
\text { É } \\
\text { LUGAR }\end{array}$} & \multirow{4}{*}{$\begin{array}{l}\text { CASA } \rightarrow \\
\text { DEUS }\end{array}$} & \multirow{4}{*}{$\begin{array}{c}\text { Na casa de meu Pai há } \\
\text { muitas moradas. Se não } \\
\text { ter-vos-ia dito (que): } \\
\text { "Vou preparar-vos um } \\
\text { lugar"? } \\
\text { (Jo 14,2) }\end{array}$} \\
\hline $\begin{array}{l}\text { Ó Deus, nós meditamos } \\
\text { teu amor no meio do teu } \\
\text { Templo! (S1 48, 10) }\end{array}$ & \multirow{4}{*}{$\begin{array}{c}\text { TEMPLO } \rightarrow \\
\text { DEUS } \\
\text { JERUSALÉM } \rightarrow \\
\text { DEUS }\end{array}$} & & & \\
\hline $\begin{array}{c}\text { Se nos sobrevier alguma } \\
\text { desgraça, guerra, } \\
\text { punição, peste ou fome, } \\
\text { compareceremos diante } \\
\text { deste Templo e diante de } \\
\text { Ti, pois teu Nome está } \\
\text { neste Templo. Do fundo de } \\
\text { nossa angústia gritaremos } \\
\text { a ti, tu nos ouvirá e nos } \\
\text { salvarás. }(2 \mathrm{Cr} 20,9) \\
\end{array}$ & & & & \\
\hline $\begin{array}{l}\text { Esta é a lei do Templo, } \\
\text { sobre o cume do monte: } \\
\text { todo o espaço em torno será } \\
\text { santíssimo (tal será a lei } \\
\text { para o Templo). (Ez 43-12) }\end{array}$ & & & & \\
\hline $\begin{array}{l}\text { Ó Deus, as nações } \\
\text { invadiram tua herança, } \\
\text { profanaram teu sagrado } \\
\text { Templo, fizeram de } \\
\text { Jerusalém um monte de } \\
\text { ruínas. }(\mathrm{Sl}, 79,1)\end{array}$ & & & $\begin{array}{c}\text { JERUSALÉM } \rightarrow \\
\text { DEUS }\end{array}$ & $\begin{array}{c}\text { Diz-lhe a mulher: Senhor, } \\
\text { vejo que tu és profeta. } \\
\text { Os nossos pais naquela } \\
\text { montanha adoraram, e vós } \\
\text { dizeis que: em Jerusalém } \\
\text { é o lugar onde se deve } \\
\text { adorar. } \\
\text { (Jo } 4,19-20)\end{array}$ \\
\hline
\end{tabular}




\section{CESPUC \\ 20 SEMESTRE DE $2019-$ N. 35}

\section{Luciama Cangussu Prates}

\begin{tabular}{|c|c|c|c|c|}
\hline $\begin{array}{c}\text { EXPRESSÕES METAFÓRICAS } \\
\text { DO ANTIGO TESTAMENTO } \\
\rightarrow\end{array}$ & $\begin{array}{l}\text { PROJEÇÃO } \\
\text { MAPPING } \\
\rightarrow\end{array}$ & $\begin{array}{c}\text { METÁFORA } \\
\text { CONCEPTUAL } \\
\rightarrow \leftarrow\end{array}$ & $\begin{array}{l}\text { PROJEÇÃO } \\
\text { MAPPING } \\
\leftarrow\end{array}$ & $\begin{array}{c}\text { EXPRESSÕES } \\
\text { METAFÓRICAS } \\
\text { DO QUARTO EVANGELHO } \\
\leftarrow\end{array}$ \\
\hline \begin{tabular}{|c|} 
Assim diz o Senhor Iahweh: \\
Nenhum estrangeiro, \\
incircunciso de coração \\
e incircunciso de corpo \\
entrará no meu santuário, \\
dentre todos os estrangeiros \\
que vivem entre os israelitas \\
. (Ez 44,9) \\
Conduziume-me então \\
para o pórtico exterior do \\
santuário, que dava para \\
o oriente, o qual estava \\
fechado. Iahweh me disse: \\
Este pórtico ficará fechado. \\
Não se abrirá e ninguém \\
entrará por ele, porque \\
por ele entrou Iahweh, o \\
Deus de Israel, pelo que \\
permanecerá fechado. (Ez \\
$44,1-2$ ) \\
Faze-me um santuário, para \\
que eu possa habitar no \\
meio deles. (Ex 25,8) \\
\end{tabular} & $\begin{array}{c}\text { SANTUÁRIO } \rightarrow \\
\text { DEUS }\end{array}$ & $\begin{array}{l}\text { DEUS } \\
\text { É } \\
\text { LUGAR }\end{array}$ & $\begin{array}{c}\text { ANTUÁRIO } \rightarrow \\
\text { DEUS } \\
\text { CORPO } \rightarrow \\
\text { DEUS }\end{array}$ & $\begin{array}{l}\text { Respondeu Jesus e disse- } \\
\text { lhes: Desfazei este } \\
\text { santuário e em três dias } \\
\text { o erguerei. Disseram, pois, } \\
\text { os judeus: Durante quarenta } \\
\text { e seis anos foi construído } \\
\text { este santuário. E tu em } \\
\text { três dias o erguerás? -Ele } \\
\text { porém falava do santuário } \\
\text { de seu corpo. } \\
\text { (Jo, 2, 19-21) }\end{array}$ \\
\hline
\end{tabular}

As categorias mais concretas ABRIGO, CASA, FORTALEZA, TORRE, TEMPLO, JERUSALÉM, SANTUÁRIO e CORPO se vinculam ao Domínio de Origem LUGAR e este, quando projetado para o Domínio Alvo DEUS, evidencia a metáfora conceptual DEUS É LUGAR.

Ainda, percebe-se que os semitas também tinham experiências de Deus em termos de elementos naturais que materializavam providências, como nutrição e saciedade (maná, fonte de água, vinho, carne, gordura). Casando essa informação com o Quarto Evangelho, verifica-se que Jesus resume, discursivamente, as referidas categorias.

Já que o homem procura a salvação dentro do cenário da natureza, a Sagrada Escritura também alude a conceitos de índole científica (física, astronômica, biólogica, etc.). Estas noções profanas da Bíblia servem de mero veículo; não são visadas em si, mas em função de proposições religiosas. (...) Tais noções, embora imperfeitas aos olhos do homem moderno, eram suficientes para designar o mundo visível e suas relações com Deus. (BITTENCOURT, 1956, p. 30.31) 
Quadro 4: DEUS É ALIMENTO

\begin{tabular}{|c|c|c|c|c|}
\hline $\begin{array}{c}\text { EXPRESSÕES METAFÓRICAS } \\
\text { DO ANTIGO TESTAMENTO } \\
\rightarrow\end{array}$ & $\begin{array}{l}\text { PROJEÇÃO } \\
\text { MAPPING } \\
\rightarrow\end{array}$ & $\begin{array}{c}\text { METÁFORA } \\
\text { CONCEPTUAL } \\
\rightarrow \leftarrow\end{array}$ & $\begin{array}{l}\text { PROJEÇÃO } \\
\text { MAPPING } \\
\leftarrow\end{array}$ & $\begin{array}{c}\text { EXPRESSÕES METAFÓRICAS } \\
\text { DO QUARTO EVANGELHO } \\
\leftarrow\end{array}$ \\
\hline \multirow{2}{*}{$\begin{array}{c}\text { Para os alimentar fez } \\
\text { chover o maná, deu } \\
\text { para eles o trigo do céu. } \\
\text { Cada um comeu o pão } \\
\text { dos Fortes; mandou-lhes } \\
\text { provisões em fartura. (S1 } \\
78,24-25 \text { ) }\end{array}$} & \multirow{3}{*}{$\begin{array}{c}\text { MANÁ } \rightarrow \\
\text { DEUS } \\
\text { PÃO } \rightarrow \text { DEUS } \\
\text { TRIGO } \rightarrow \\
\text { DEUS }\end{array}$} & \multirow{4}{*}{$\begin{array}{c}\text { DEUS } \\
\stackrel{E}{\text { E }} \\
\text { ALIMENTO }\end{array}$} & \multirow{4}{*}{$\begin{array}{l}\mathrm{PA} O \rightarrow \\
\text { DEUS }\end{array}$} & $\begin{array}{l}\text { Respondeu Jesus e disse-lhe: } \\
\text { Todo o bebendo desta água } \\
\text { terá sede de novo; Quem } \\
\text { (porém) beber da água da qual } \\
\text { eu lhe der não terá sede em } \\
\text { eternidade, mas a água que } \\
\text { eu lhe der virá-a-ser nele uma } \\
\text { fonte de água jorrando para a } \\
\text { vida eterna. } \\
\text { (Jo 4,13-14) }\end{array}$ \\
\hline & & & & $\begin{array}{l}\text { Respondeu-lhes Jesus e disse: } \\
\text { Amém, amém, digo-vos: } \\
\text { "Procurais-me não porque } \\
\text { vistes sinais, mas porque } \\
\text { comestes dos pães e vos } \\
\text { fartastes". Obrai não a comida } \\
\text { que perece mas a comida que } \\
\text { permanece para vida eterna, } \\
\text { que o Filho do Homem vos } \\
\text { dará. Pois a este o pai marcou } \\
\text { com seu selo, Deus. } \\
\text { (Jo 6,26-27) }\end{array}$ \\
\hline \multirow{2}{*}{$\begin{array}{c}\text { Comereis tutano } \\
\text { até vos fartardes e } \\
\text { bebereis sangue até vos } \\
\text { embriagardes com o } \\
\text { sacrifício que vos ofereço. } \\
(\text { Ez 39,19) }\end{array}$} & & & & $\begin{array}{l}\text { Disse-lhes pois Jesus: Amém, } \\
\text { amém, digo-vos: "Não Moisés } \\
\text { deu-vos o pão do céu, mas o } \\
\text { meu Pai dar-vos-á o verdadeiro } \\
\text { pão do céu". Pois o pão de } \\
\text { Deus é o que desce do céu e dá } \\
\text { vida ao mundo. } \\
\text { (Jo 6, 32-33) }\end{array}$ \\
\hline & $\begin{array}{l}\text { TUTANO } \rightarrow \\
\text { DEUS } \\
\text { SANGUE } \rightarrow \\
\text { DEUS }\end{array}$ & & & $\begin{array}{l}\text { Disse-lhes Jesus: Eu sou o pão } \\
\text { da vida. O vindo a mim não } \\
\text { mais terá fome e o acreditando } \\
\text { em mim não terá sede nunca. } \\
\text { (Jo 6,35) }\end{array}$ \\
\hline
\end{tabular}




\begin{tabular}{|c|c|c|c|c|}
\hline $\begin{array}{c}\text { EXPRESSÕES METAFÓRICAS } \\
\text { DO ANTIGO TESTAMENTO } \\
\rightarrow\end{array}$ & $\begin{array}{l}\text { PROJEÇÃO } \\
\text { MAPPING } \\
\rightarrow\end{array}$ & $\begin{array}{c}\text { METÁFORA } \\
\text { CONCEPTUAL } \\
\rightarrow \leftarrow\end{array}$ & $\begin{array}{l}\text { PROJEÇÃO } \\
\text { MAPPING } \\
\leftarrow\end{array}$ & $\begin{array}{c}\text { EXPRESSÕES METAFÓRICAS } \\
\text { DO QUARTO EVANGELHO } \\
\leftarrow\end{array}$ \\
\hline $\begin{array}{c}\text { Alimentarei os sacerdotes } \\
\text { com gordura e meu povo } \\
\text { se saciará com meus bens } \\
\text { - oráculo de Iahweh. (Jr } \\
31,14)\end{array}$ & $\begin{array}{l}\text { GORDURA } \rightarrow \\
\text { DEUS } \\
\text { SANGUE } \rightarrow \\
\text { DEUS }\end{array}$ & \multirow{4}{*}{$\begin{array}{c}\text { DEUS } \\
\text { É } \\
\text { ALIMENTO }\end{array}$} & \multirow{2}{*}{$\begin{array}{l}\mathrm{PÃO} \rightarrow \\
\mathrm{DEUS} \\
\mathrm{CARNE} \rightarrow \\
\text { DEUS }\end{array}$} & \\
\hline \multirow{3}{*}{$\begin{array}{l}\text { Sou como bêbado, como } \\
\text { homem que o vinho } \\
\text { dominou por causa Iahweh } \\
\text { e por causa de suas santas } \\
\text { palavras. }(\mathrm{Jr} 23,9)\end{array}$} & \multirow{3}{*}{$\begin{array}{l}\text { VINHO } \rightarrow \\
\text { DEUS }\end{array}$} & & & $\begin{array}{c}\text { Eu sou o pão vivo que desceu } \\
\text { do céu: se alguém comer deste } \\
\text { pão viverá para sempre. E o } \\
\text { pão que eu darei é a minha } \\
\text { carne para a vida do mundo. } \\
\text { (Jo 6:5l) }\end{array}$ \\
\hline & & & $\begin{array}{c}\text { CARNE } \rightarrow \\
\text { DEUS } \\
\text { SANGUF } \rightarrow\end{array}$ & $\begin{array}{l}\text { Disse-lhes pois Jesus: Amém, } \\
\text { amém, digo-vos: "Se não } \\
\text { comerdes a carne do Filho } \\
\text { do Homem e beberdes o seu } \\
\text { sangue, não tendes vida em } \\
\text { vós mesmos". O mastigando } \\
\text { minha carne e bebendo meu } \\
\text { sangue, tem vida eterna e eu } \\
\text { o ressuscitarei no último dia. } \\
\text { Pois minha carne é verdadeira } \\
\text { comida. } \\
\text { (Jo 6, 53-55) }\end{array}$ \\
\hline & & & $\begin{array}{l}\text { DEUS } \\
\text { VIDEIRA } \rightarrow \\
\text { DEUS }\end{array}$ & $\begin{array}{l}\text { Permanecei em mim e eu } \\
\text { em vós. Assim como o ramo } \\
\text { não pode produzir fruto de si } \\
\text { mesmo se não permanecer na } \\
\text { videira, assim também não vós, } \\
\text { se não em mim permanecerdes } \\
\text { Eu sou a videira, vós os ramos. } \\
\text { O que permanece em mim -e } \\
\text { eu nele- este produz muito } \\
\text { fruto. } \\
\text { porque fora de mim não podeis } \\
\text { fazer nada. } \\
\text { (Jo } 15,4-5 \text { ) }\end{array}$ \\
\hline
\end{tabular}




\begin{tabular}{|c|c|c|c|c|}
\hline $\begin{array}{c}\text { EXPRESSÕES METAFÓRICAS } \\
\text { DO ANTIGO TESTAMENTO } \\
\rightarrow\end{array}$ & $\begin{array}{l}\text { PROJEÇÃO } \\
\text { MAPPING } \\
\longrightarrow\end{array}$ & $\begin{array}{l}\text { METÁFORA } \\
\text { CONCEPTUAL } \\
\quad \rightarrow \leftarrow\end{array}$ & $\begin{array}{l}\text { PROJEÇÃO } \\
\text { MAPPING } \\
\leftarrow\end{array}$ & $\begin{array}{c}\text { EXPRESSÕES METAFÓRICAS } \\
\text { DO QUARTO EVANGELHO } \\
\leftarrow\end{array}$ \\
\hline $\begin{array}{c}\text { Bendito o homem que } \\
\text { se fia em Iahweh, cuja } \\
\text { confiança é Iahweh. Ele é } \\
\text { como uma árvore plantada } \\
\text { junto da água, que lança } \\
\text { suas raízes para a corrente: } \\
\text { não teme quando chega } \\
\text { o calor, sua folhagem } \\
\text { permanece verde; em ano } \\
\text { de seca não se preocupa } \\
\text { e não para de produzir } \\
\text { frutos. (Jr 17,7-8) }\end{array}$ & $\begin{array}{l}\text { ÁGUA } \rightarrow \\
\text { DEUS }\end{array}$ & $\begin{array}{c}\text { DEUS } \\
\stackrel{E}{\text { E }} \\
\text { ALIMENTO }\end{array}$ & $\begin{array}{c}\text { ÁGUA } \rightarrow \\
\text { DEUS }\end{array}$ & $\begin{array}{l}\text { No último dia, o principal, } \\
\text { da festa, estava posto Jesus e } \\
\text { exclamou dizendo: "Se alguém } \\
\text { tiver sede, venha a mim e beba } \\
\text { o acreditando em mim.» Assim } \\
\text { como diz a escritura: Do seu } \\
\text { interior fluirão rios de água } \\
\text { viva. } \\
\text { (Jo } 7,37-38)\end{array}$ \\
\hline
\end{tabular}

As categorias mais concretas MANÁ, PÃO, TRIGO, TUTANO, GORDURA e CARNE se vinculam ao Domínio de Origem NUTRIÇÃO e este, quando projetado para o Domínio Alvo DEUS, evidencia a metáfora conceptual DEUS É ALIMENTO. Paralelamente, ÁGUA, SANGUE e VINHO se ligam ao Domínio de Origem SACIEDADE que, por sua vez, evidencia a metáfora conceptual DEUS É ALIMENTO.

Em resumo, diante das evidências textuais, percebe-se que João, fortemente marcado pela hermenêutica e exegese rabínicas, associa as metáforas conceptuais DEUS É CORPO, DEUS É ATIVIDADE, DEUS É LUGAR e DEUS É ALIMENTO à figura de Jesus Cristo. Notadamente vinculadas à cognição judaica, tais metáforas conceptuais, no Quarto Evangelho, estão condensadas na Encarnação do Filho (visão cristã), o qual, a partir da linha de raciocínio criada, realmente funciona como um Domínio de Origem.

Portanto, DEUS É JESUS pode ser vista como uma metáfora conceptual no sentido de ser uma síntese de todas as mencionadas. Neste caso, DEUS É JESUS não se enquadra no grupo das METÁFORAS CONCEPTUAIS ESTRUTURAIS, pois não ocorre apenas no sentido de organizar metaforicamente um conceito em termos de outro (DEUS É JESUS se vincula a uma complexa rede de conceitos). DEUS É JESUS também não se encaixa no grupos das METÁFORAS CONCEPTUAIS ORIENTACIONAIS, uma vez que não se restringe apenas às noções espaciais para estruturar todo um sistema de conceitos em termos de outro. Analisando os jogos estabelecidos entre as expressões metafóricas presentes no Antigo Testamento e no Novo Testamento, acredita-se que DEUS É JESUS, pelo alto nível de elaboração, vincula-se ao grupo das METÁFORAS CONCEPTUAIS ONTOLÓGICAS, as quais favorecem as maneiras de se conceber os eventos, as atividades, as emoções e as ideias vinculadas à experiência de DEUS como uma entidade específica: JESUS.

Assim faz sentido João apresentar expressões metafóricas do tipo "A Palavra era Deus" 
20 SEMESTRE DE 2019 - N. 35

(Jo 1,1), "Não estou só, mas eu e o Pai que me mandou" (Jo 8,16); "Eu sou o testemunhando de mim mesmo e testemunha de mim o Pai que me mandou." (Jo 8,18);. "Eu e o Pai somos um" (Jo 10,30); "O servo não é maior que seu senhor, nem o enviado maior que o que o mandou" (Jo 13, 16); "Eu sou o caminho e a verdade e a vida, ninguém vai ao Pai senão por mim" (Jo 14, 6); "Se me conheceis, também a meu Pai conhecereis" (Jo 14, 7), "Quem me viu, viu o Pai" (Jo 14,9); "Acreditai-me, eu estou no Pai e o Pai está em mim”. Tais frases sugerem que João convida os leitores a experimentarem DEUS em termos de JESUS.

Finalizando o raciocínio, as metáforas conceptuais judaicas, DEUS É CORPO, DEUS É ATIVIDADE, DEUS É LUGAR e DEUS É ALIMENTO, por sua vez, estão inseridas, numa perspectiva neotestamentária, na metáfora conceptual DEUS É JESUS. Numa análise geral, pode-se dizer que no nível linguístico-cognitivo há as seguintes projeções:

ANTIGO TESTAMENTO

DOMÍNIOS DE ORIGEM JUDAICO

CORPO, ATIVIDADE, LUGAR, NUTRIÇÃO, SACIEDADE, LUZ, ENVIAR, ALTO

DOMÍNIO ALVO

DEUS

Pelos resultados, infere-se que João, influenciado por tais projeções presentes nas experiências da fé judaica, construiu a sua narrativa a fim de mostrar que Jesus é o grande mediador entre a humanidade e Deus. Como visto, as categorias utilizadas por ele a fim de fortalecer o tom cristológico de sua teologia são as mesmas presentes nas metáforas conceptuais que emergem do Antigo Testamento. Assim, o Domínio de Origem JESUS realmente é a síntese daqueles presentes no judaísmo.

QUARTO EVANGELHO

DOMÍNIOS DE ORIGEM JUDAICO

CORPO, ATIVIDADE, LUGAR, NUTRIÇÃO, SACIEDADE

$\downarrow$

DOMÍNIO DE ORIGEM CRISTÃO

JESUS CRISTO

DOMÍNIO ALVO

DEUS 


\section{CESPUC \\ 20 SEMESTRE DE $2019-$ N. 35}

\section{Luciama Cangussu Prates}

\section{CONCLUSÃO}

A leitura do Quarto Evangelho à luz dos princípios da TMC oferece ferramentas para compreendermos como as metáforas conceptuais identificadas colaboram para a produção de sentidos para Deus e, assim, demonstra como tais processamentos metafóricos influenciam a compreensão sobre a teologia joanina. Reconhecemos que esse quadro teórico escolhido (ou qualquer outra teoria de metáfora) não é capaz de englobar alguns aspectos vinculados às circunstâncias culturais da produção do referido texto evangélico. Todavia, verificamos que as metáforas conceptuais para Deus elencadas, apesar de restritas a uma lente muito específica de análise, levantam algumas ponderações importantes para aqueles que se interessam pelo assunto.

Quando relacionamos o termo "Deus" com a TMC, percebemos que a mente e a razão, por serem "corporificadas", ou melhor, estruturadas a partir das experiências corporais e das peculiaridades do corpo, fundamentam o desenvolvimento das faculdades de percepção dos sujeitos em torno da espiritualidade. Estes, por sua vez, mesmo sem terem acesso claro a todos os processos vinculados aos mecanismos que são ativados quando produzem enunciados linguísticos para expressarem suas respectivas compreensões sobre Deus, vivem o fenômeno da metáfora conceptual como operação da consciência, isto é, como aparato cognitivo que orienta a audição, a fala, o olfato, o tato, a visão e a ação de uma forma específica.

Por fim, observamos que as metáforas conceptuais DEUS É CORPO, DEUS É ATIVIDADE, DEUS É LUGAR e DEUS É ALIMENTO não só interferem no modo de agir do ser humano, como também criam novas bases de experiência que, por sua vez, podem gerar novas formas de conceptualizar Deus. Por se tratar de um mecanismo conceptual e cognitivo que permite explicar uma ideia em termos de outra, partindo da experiência corporal para categorizar Deus, que linguisticamente é abstrato, as novas experiências em torno do tema só podem ser entendidas na medida em que se integram a conhecimentos anteriores. A partir do exposto, faz sentido relacionar a metáfora conceptual síntese DEUS É JESUS, visualizada pela leitura do Quarto Evangelho, com aquelas que foram mapeadas a partir do pensamento judaico do Antigo Testamento e, a partir disso, inferir como elas subjazem à forma de pensar/ falar Deus na comunidade cristã dos dias de hoje. 


\section{CESPUC \\ 20 SEMESTRE DE $2019-$ N. 35}

\section{REFERÊNCIAS}

AMARAL, Patrícia. "Metáfora e Linguística Cognitiva". In SILVA, A. S. (Org.). Linguagem e Cognição: a Perspectiva da Linguística Cognitiva. Braga: Associação Portuguesa de Linguística e Universidade Católica Portuguesa, 2001.

BATORÉO, Hanna Jakubowicz. Expressão do Espaço no Português Europeu. Contributo Psicolinguístico para o Estudo da Linguagem e Cognição. Lisboa: Fundação Calouste Gulbenkian, Fundação para a Ciência e a Tecnologia (Dissertação de Doutoramento apresentada à FLUL em 1996), 2000.

BEUTLER, Johannes. Das Johannesevangelium: Kommentar. Freiburg: Herder, 2013.

BITTENCOURT, Dom Estêvão. Para entender o Antigo Testamento. Rio de Janeiro, Livraria Agir Editora, 1956.

DODD, Charles. The Interpretation of the Fourth Gospel. Cambridge University Press, London, 1970.

LAKOFF, George; JOHNSON, Mark. Coord. da tradução: Mara Sophia Zanotto. Metáforas da vida cotidiana. Mercado de letras, Campinas, São Paulo, Brasil, 2002.

LAKOFF. Metaphors we live by. The University of Chicago Press; Chicago, United States of America, 1980.

LIMA, Paula Lenz Costa. "Metáfora e Linguagem". In FELTES, Moraes (Org.). Produção de Sentido. Estudos Interdisciplinares. São Paulo: Annablume; Porto Alegre: Nova Prova; Caxias do Sul: Educs, 2001.

MANNS, Frédéric. L'Evangile de Jean à lumière du Judaisme. Franciscan Printing Press, Jerusalem, 1991.

MANNS, Frédéric. L'Israel de Dieu. Essais sur le christianisme primitif. Franciscan Printing Press, Jerusalem, 1996.

WRIGHT, Nicholas Thomas. Os desafios de Jesus. A escolha de ser um verdadeiro seguidor de Jesus. Brasília, DF: Palavra, 2012. 